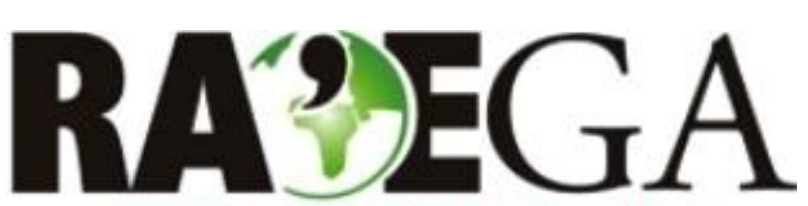

O ESPACYO GEOGRÁFICO EM ANÁLISE

\title{
MODERNIZAÇÃO DO LITORAL E O ESTILHAÇAMENTO DA VIDA COTIDIANA: O CASO DE CUMBUCO - CAUCAIA (CE)
}

\section{MODERNIZATION OF THE COAST AND THE SHATTERING OF EVERYDAY LIFE: THE CASE OF CUMBUCO - CAUCAIA (CE)}

\author{
Eider Olivindo Cavalcante \\ Doutorando em Geografia pela Universidade Federal do Ceará \\ Universidade Federal do Ceará - UFC \\ Fortaleza, CE, Brasil \\ e-mail: eidervcavalcante@hotmail.com
}

Recebido em:

Aceito em:

\section{Resumo}

Até o final da década de 1970, que marca a propagação dos conflitos com especuladores imobiliários e grileiros, o litoral do Ceará representava um sinônimo de liberdade para remanescentes indígenas e outros agrupamentos humanos que historicamente habitaram o litoral ou que migraram de outras partes do estado fortemente funcionalizadas pelas atividades da pecuária e da agricultura. Todavia, no contexto da busca de novos territórios e setores para a acumulação capitalista, como também da captura tempo livre e das demais relações sociais que escapavam à lógica da (re)produção das relações de produção capitalista, o litoral passou a ser fortemente funcionalizado como território turístico. Nesse contexto, destacou-se a localidade do Cumbuco histórica comunidade pesqueira marítima localizada no município de Caucaia enquanto recorte espacial, procurando analisar a mudança do modo de vida no/do Cumbuco, modo que até décadas passadas era caracterizado pelo tempo lento, pelas atividades ligadas a pesca artesanal, confecção de bordados, labirintos e crochês, cultivo de vazante, religiosidade, e por todo um leque de práticas e representações de mundo. No desenrolar histórico, entretanto, esse modus vivendi foi subordinado à lógica da mercadoria e estilhaçado em vários percursos e atrações para turistas, veranistas e investidores. As relações concretas construídas pelos cumbuqueiros com 0 território de uso foram substituídas por uma série de relações simuladas e abstratas, reguladas em prol das atividades econômicas ali instaladas. 
Palavras-chave: Urbanização; Turismo; Comunidade.

\begin{abstract}
Until the end of 1970s, when the first conflicts between real estate speculators and land grabbers broke out, the coast of Ceará had remain a land of freedom for remaining indigenous people and other human groups that historically inhabited the coast or migrated from other parts of the state where agriculture and livestock activities largely prevail. However, in the context of the search for new territories and sectors to capitalist accumulation, as well as due to the capture of free time and social relationships that escaped the logic of (re)production of capitalist relations, the coast has been strongly reorganized as tourist territory. In this context was stood out the locality of Cumbuco - a historic maritime fishing community situated in the county of Caucaia - while spatial clipping, trying to investigate about the lifestyle changes in/of Cumbuco, which during the last decades was characterized by slow time, activities related of handmade fishing, embroidery, laces of labyrinth and crochet, cultivation of ebb, religiosity, and a whole range of practices and representations of the world. However, in the course of history, this modus vivendi was subordinated to the logic of the merchandise and splintered on several routes and attractions for tourists, vacationers and investors. The concrete relationships built by cumbuqueiros to the territory of use were replaced by a series of simulated and abstract relations, regulated in favor of economic activities there established.
\end{abstract}

Keywords: Urbanization; Tourism; Community.

\title{
1. INTRODUÇÃO
}

O estado do Ceará vem passando, nas últimas décadas, por importantes mudanças em sua dimensão socioespacial, transformações que ocorrem principalmente em função da introdução de "novas" dinâmicas da racionalização capitalista no estado, destacando-se o turismo, desenvolvido principalmente no litoral cearense, como também outros vetores de modernização frutos da reestruturação socioespacial capitalista, a saber: o agronegócio nos vales úmidos e a atividade industrial no Cariri Cearense, em Sobral e na Região Metropolitana de Fortaleza. Esses territórios, antes "neutros" para a acumulação, hoje são estratégicos e seletivos para a reprodução capitalista no estado do Ceará, consubstanciando-se como verdadeiros pontos luminosos que contrastam fortemente com a paisagem cearense predominante (LIMA, L., 2007). 
O litoral, foco desta análise, tem como principal catalisador de transformação a atividade turística que vem se consolidando cada vez mais no estado devido a diversos fatores, entre os quais Coriolano e Fernandes (2005) destacam: possibilidades de acesso a todo o território cearense; criação de atrativos naturais e culturais para o turista; qualidade profissional dos serviços prestados; os equipamentos turísticos; marketing.

O Ceará, com uma extensa linha de costa de $573 \mathrm{~km}$, passa por um processo de implantação de melhorias na infraestrutura viária e de serviços por meio do poder estatal e de parcerias público/privadas, que propicia a implantação de uma série de empreendimentos imobiliários e turísticos, além de toda uma construção de "vocação turística" no imaginário cearense e da sociedade em geral.

Nesse sentido, o artigo que ora se apresenta é resultado de uma pesquisa que tem como objetivo compreender os conflitos, as mudanças e permanências da localidade do Cumbuco diante da modernização do litoral cearense, que traz consigo uma série de contradições capitaneadas principalmente pelo turismo e pela urbanização ${ }^{1}$. O trabalho concentra-se na mudança do modo de vida no/do Cumbuco, que até decênios passados era caracterizado pelo tempo lento, pela predominância da pesca artesanal; pela confecção de bordados, de labirintos e crochês; pelo cultivo de vazantes; pela religiosidade, e por todo um leque de práticas e representações de mundo. No desenrolar histórico, entretanto, esse modus vivendi foi subordinado à lógica da mercadoria e estilhaçado pela força do espaço abstrato. Todavia, mesmo que o olhar esteja voltado sobretudo para os cumbuqueiros, tenciona-se obter um entendimento do Cumbuco por inteiro, particularmente no tocante a sua inserção na modernização seletiva do litoral cearense.

\section{MATERIAIS E MÉTODOS}

\footnotetext{
${ }^{1} \mathrm{O}$ presente artigo materializa-se enquanto parte dessa pesquisa realizada junto ao Programa de Pós-Graduação em Geografia da Universidade Federal do Ceará - sob financiamento da Fundação Cearense de Apoio ao Desenvolvimento Científico e Tecnológico (FUNCAP) - para a obtenção do título de Mestre em Geografia.
} 
A pesquisa apoia-se no método regressivo-progressivo de Henri Lefebvre na tentativa de uma aproximação da realidade do Cumbuco, procurando lançar mão de um processo de travessia que percorra os caminhos do presente ao passado e do presente ao possível, considerando os vários momentos do real, buscando chegar ao espaço geográfico e seu conteúdo.

No intento de construir uma pesquisa de caráter qualitativo, mesmo que permeada também da análise quantitativa, utilizou-se a observação ativa de Haguette (1997), com base na vivência com a vida no Cumbuco, participando das reuniões da colônia; da festa do padroeiro; da comemoração do aniversário da vila de pescadores; de algumas intervenções culturais; de atividades com a associação. Não se deixou também de caminhar atento nas areias do Cumbuco, e de encetar conversas informais durante os períodos de estada no local.

Tomando como base a orientação da entrevista centrada de Haguette (1997) e da entrevista em profundidade de Minayo (2008), pôde-se construir uma série de entrevistas, que aliadas aos valiosos documentos conseguidos com a colônia e o trabalho de Pinho (1981), foram primordiais tanto para a decomposição da descrição da manifestação formal do Cumbuco e seguir caminho por sua formação territorial quanto para a obtenção das pistas da coexistência de tempos históricos do Cumbuco contemporâneo.

\section{RESULTADOS E DISCUSSÃO}

\subsection{Cumbuco e sua manifestação formal}

Cumbuco, localizado aproximadamente a $30 \mathrm{~km}$ (oeste) de Fortaleza, cercado de dunas, coqueiros e do mar, é uma das praias do litoral cearense mais procuradas pelos turistas e o lócus de uma pequena vila de pescadores (Vila do Cumbuco) em meio a grandes hotéis, pousadas, barracas de praia, boates, resorts, condomínios, mansões, lojas e toda uma infraestrutura que vem propiciar uma dinâmica que não existia no local há algumas décadas.

Essa pequena vila se consubstancia como residência de uma parte dos pescadores artesanais marítimos da localidade, que tiram da labuta pesqueira, 
em meio ao sol e ao mar, o sustento diário de suas famílias. Pescadores que, além de todas as dificuldades diárias do ato de pescar em uma pequena jangada, paquete ou bote, enfrentam ainda, por exemplo: a crise atual da pesca artesanal; o fato de grande parte das embarcações serem propriedade de armadores $^{2}$ e os conflitos com os atravessadores (marchantes). Além disso, hoje esses trabalhadores do mar têm, ainda, sua rotina bombardeada por todo um leque de novos conflitos e contradições que colocam em cheque a reprodução dos mesmos enquanto cumbuqueiros ${ }^{3}$.

Sobre uma amenidade natural, um campo de dunas móveis, pouco antes da entrada do Cumbuco, pode-se ver, também, uma ocupação denominada Parazinho, fruto da saída de pescadores e filhos de pescadores de suas antigas residências, os quais estão construindo suas moradias sobre as dunas, distante do local de trabalho e convívio.

Cumbuco localiza-se no distrito sede do município de Caucaia, que se configura como o segundo maior município do estado do Ceará no tocante à população, situando-se na Região Metropolitana de Fortaleza. Nesse sentido, Cumbuco tem uma posição privilegiada, pois, como bem observa Dantas (2010), o turismo cearense é predominantemente litorâneo e metropolitano.

Caucaia possui uma economia gerada principalmente pelo setor de serviços, que totaliza $67,7 \%$ do PIB do município, seguido pela indústria, com $29,86 \%$, e pela agropecuária, com 2,44\% (IPECE, 2008). O setor mais ativo também é responsável pela geração de $32,13 \%$ dos empregos formais existentes em Caucaia. Segundo Teles (2005, p. 125), o setor terciário desempenha um papel fundamental na vida econômica da cidade. A autora afirma que, nos últimos dez anos "[...] este setor aumentou significativamente em decorrência da demanda crescente tanto por parte da população residente, como também da população flutuante que frequenta o município, sobretudo nos finais de semana, feriados e meses de férias". Ainda segundo Teles (2005, p. 130-131), “[...] o caráter da terceirização concentra-se, principalmente, nas

\footnotetext{
${ }^{2}$ Segundo Diegues (1995), o armador de pesca é o proprietário de várias embarcações, mas não realiza a atividade da pesca.

${ }^{3}$ Como são conhecidos os "nativos" do Cumbuco.
} 
atividades turísticas, em especial de alojamento e de transporte, além das agências de viagens".

Caucaia, que tem Cumbuco como principal destino turístico, figura em primeiro lugar no ranking do número de turistas que ingressam no estado do Ceará via Fortaleza, seguido dos municípios de Aracati, Beberibe e Jijoca (SETUR, 2009b). Em outra pesquisa apresentada pela Setur (2009a), fazendo uma relação de dados entre 1999 e 2008, a praia do Cumbuco constitui-se como a preferida dos turistas, seguida pela de Canoa Quebrada, no município de Aracati.

Quadro 1 - Praias cearenses preferidas pelos turistas*

\begin{tabular}{|l|l|l|l|}
\hline Praias & $\mathbf{1 9 9 9}$ & Praias & $\mathbf{2 0 0 8}$ \\
\hline Cumbuco & 19,2 & Cumbuco & 16,1 \\
Canoa Quebrada & 15,3 & Canoa Quebrada & 14,2 \\
Morro Branco & 11,7 & Jericoacoara & 9,5 \\
Porto das Dunas & 9,1 & Icaraí & 8.2 \\
Jericoacoara & 7,0 & Morro Branco & 7.4 \\
Icaraí & Prainha & 5,3 \\
Lagoinha & 6,6 & Porto das Dunas & 4,8 \\
Praia das Fontes & 4,6 & lguape & 4,4 \\
Outras & Outras & 30,1 \\
\hline Total & $\mathbf{1 0 0 , 0}$ & Total & $\mathbf{1 0 0 , 0}$ \\
\hline
\end{tabular}

Fonte: SETUR/CE (2009a).

*Excluído o litoral de Fortaleza

Cumbuco é uma das exceções turísticas do Ceará, já que neste estado, ainda que as intenções iniciais dos gestores ${ }^{4}$ e dos empresários visassem os turistas estrangeiros, o turismo é predominantemente composto por brasileiros, que representam 92,27 \% da demanda (SETUR, 2012). No entanto, em Cumbuco o universo turístico é constituído principalmente por estrangeiros, a maioria deles portugueses, suecos, finlandeses e noruegueses.

Associa-se à atividade do turismo uma nova efervescência imobiliária em Cumbuco nos últimos anos, principalmente no que diz respeito às segundas residências, as quais, por sinal, representaram a primeira fonte de exploração econômica da localidade mediante a construção do Loteamento

\footnotetext{
${ }^{4}$ Benevides $(1998,2003)$ destaca a intenção do Ceará de se constituir como um polo receptor da afluente demanda de setores de alta renda provenientes de vários países da economia pós-industrial.
} 
Praia do Cumbuco no final da década de 1970. Observa-se a construção de uma gama de empreendimentos imobiliários de grande porte, voltados para brasileiros e principalmente estrangeiros que desejam investir ou simplesmente adquirir uma segunda residência para descanso ocasional nas terras cearenses.

Caucaia está entre as principais cidades do estado do Ceará em número de residências secundárias, permanecendo em segundo lugar no ranking entre os anos de 1980 e 2000, atrás somente de Fortaleza. Em 2010, todavia, o município apresentou um decréscimo no número de residências secundárias e perdeu o segundo lugar para o município de Aquiraz ${ }^{5}$.

Quadro 2 - Municípios com maior número de domicílios de uso ocupacional

\begin{tabular}{|l|l|l|l|l|l|l|l|l|}
\hline \multirow{2}{*}{} & \multicolumn{2}{|c|}{$\mathbf{1 9 8 0}$} & \multicolumn{2}{c|}{1991} & \multicolumn{2}{c|}{$\mathbf{2 0 0 0}$} & \multicolumn{2}{c|}{$\mathbf{2 0 1 0}$} \\
\cline { 2 - 10 } & $\begin{array}{c}\text { Uso } \\
\text { permanente }\end{array}$ & $\begin{array}{c}\text { Uso } \\
\text { ocasional }\end{array}$ & $\begin{array}{c}\text { Uso } \\
\text { permanente }\end{array}$ & $\begin{array}{c}\text { Uso } \\
\text { ocasional }\end{array}$ & $\begin{array}{c}\text { Uso } \\
\text { permanente }\end{array}$ & $\begin{array}{c}\text { Uso } \\
\text { ocasional }\end{array}$ & $\begin{array}{c}\text { Uso } \\
\text { permanente }\end{array}$ & $\begin{array}{c}\text { Uso } \\
\text { ocasional }\end{array}$ \\
\hline Fortaleza & 256.710 & 1.476 & 387.597 & 4.112 & 527.340 & 7.942 & 711.470 & 15.029 \\
\hline Aquiraz & 8.792 & 1.128 & 9.823 & 2.657 & 14.127 & 4.536 & 19.707 & 6.534 \\
\hline Caucaia & 17.335 & 1.192 & 35.405 & 3.877 & 59.990 & 6.540 & 89.253 & 6.009 \\
\hline Beberibe & 6.743 & 555 & 7.743 & 1.416 & 10.030 & 2.342 & 14.107 & 3.211 \\
\hline Cascavel & 9.191 & 176 & 9.951 & 1018 & 13.702 & 1.643 & 18.832 & 2.574 \\
\hline $\begin{array}{l}\text { São } \\
\text { Gonçalo }\end{array}$ & 4.682 & 256 & 6.183 & 1.197 & 8.397 & 1.822 & 12.038 & 2.566 \\
\hline
\end{tabular}

Fonte: IBGE.

Merecedor de destaque é o fato de que dos cinco primeiros municípios no ranking do número de domicílios de uso ocupacional, afora Fortaleza, somente Beberibe não faz parte da Região Metropolitana de Fortaleza, apesar de distar somente $75 \mathrm{~km}$ da capital cearense. Nesse sentido, Pereira (2006, p. 73) afirma que "[...] veraneio no Ceará é predominantemente litorâneo, de sorte que a ocupação ocorre em duas faixas retilíneas, que tem como nó central Fortaleza e se estende pelo restante do espaço litorâneo. O espaço de maior densidade, contudo, é o litorâneo metropolitano".

\footnotetext{
${ }^{5}$ Silveira (2011) aponta que uma das principais motivações para tal decréscimo seja o processo de transformação de grande parte das residências secundárias em residências principais, especialmente na localidade de Icaraí.
} 
Diferentemente de outras localidades de Caucaia, como o Icaraí, por exemplo, que na década de 1970 teve uma forte valorização associada às segundas residências de moradores da classe média de Fortaleza, os proprietários de segundas residências no Cumbuco possuem elevados níveis de renda. Conforme levantamento da Cenários Pesquisa de Marketing, realizado no primeiro semestre de $2011,42 \%$ das famílias que têm ou pretendem adquirir uma residência de praia no Cumbuco detêm renda igual ou superior a $R \$ 20$ mil. A pesquisa "apontou ainda que, de todos os proprietários ou pretensos donos de uma segunda residência no Cumbuco, $31 \%$ são empresários, $25 \%$ profissionais liberais, $18 \%$ funcionários de empresas privadas, $16 \%$ de públicas, $5 \%$ são autônomos, $3 \%$ militares e $2 \%$ aposentados" (O POVO, 22 de agosto de 2011).

Nos últimos dois anos, observa-se também a crescente presença de sul-coreanos no Cumbuco, em virtude da construção da Companhia Siderúrgica do Pecém (CSP), o que vem aquecendo o mercado imobiliário ligado às primeiras residências e trazendo consigo um leque de empreendimentos como comércios, restaurantes, imobiliárias e até templos religiosos que se dedicam a atender especificamente esse novo público na localidade praiana.

\subsection{Trilhas da formação territorial}

Após uma travessia en passant pela aparência fenomênica, segue-se caminho em busca da história do espaço, da história do Cumbuco e de sua formação territorial que se inicia aproximadamente na década de 1920, quando um pescador insatisfeito com a vida em Fortaleza decidiu viver em outro local (PINHO, 1981; VIEIRA, 2000). Essa década coincide com o período em que se inicia a ocupação da Praia de Iracema em Fortaleza por famílias da "alta sociedade" cearense (NEVES, 2004; DANTAS, 2014).

A pesca propiciou ao pescador conhecer grande parte do litoral cearense, mas ele acabou decidindo morar em uma praia distante apenas 30 $\mathrm{km}$ de Fortaleza, utilizando como transporte a própria jangada e levando consigo sua família. A praia, denominada Cumbuco, era deserta e o acesso a 
ela se dava somente pelo mar e pela faixa de praia, sendo esta última forma somente possível quando a maré estava baixa. Posteriormente, com as notícias de pesca abundante na região, tanto no mar quanto nas inúmeras lagoas existentes à época, outras famílias começaram a se transferir para a região. Em 1977, a localidade possuía 120 famílias (PINHO, 1981).

Até os finais da década de 1970, que marcaram a propagação dos conflitos com especuladores imobiliários e grileiros, o litoral representava um sinônimo de liberdade ${ }^{6}$ para remanescentes indígenas e outros agrupamentos humanos que historicamente habitaram o litoral ou que decidiram migrar do interior do estado do Ceará, fugindo de conflitos agrários e de outros processos que funcionalizavam fortemente outras partes do estado, principalmente as atividades da pecuária e da agricultura.

O litoral do Ceará, desde o período colonial, era visto como um local impróprio para a prática de atividades produtivas, como a agricultura, por exemplo, particularmente por conta das características físico-climáticas e da hostilidade indígena (LIMA, M. 2002). Nesse contexto, a ocupação portuguesa se dera somente de forma pontual no intuito de defesa do território e para o desenvolvimento da atividade portuária, com a intenção do escoamento da produção, servindo de abertura para a comercialização de produtos que atendiam tanto a demanda externa quanto a demanda dos estados produtores de cana-de-açúcar (DANTAS, 2011).

Tal realidade propiciou a consolidação de várias comunidades pesqueiras marítimas, as quais, ainda no período colonial, eram vistas com bons olhos pela Coroa, pois a marinha não tinha quadros suficientes para patrulhar a costa brasileira. Assim, em caso de algum conflito, os pescadores e suas colônias - as sentinelas avançadas do litoral - poderiam ser úteis na proteção do território, pois mesmo tido como impróprio ao desenvolvimento de atividades produtivas e não sendo objeto de distribuição das sesmarias, o litoral se configurava um território estratégico de defesa. Essa realidade se manteve, em grande medida, mesmo com o crescimento de cidades como Fortaleza,

\footnotetext{
${ }^{6}$ Como destaca Madruga (1992).
} 
Camocim, Aquiraz e Paracuru, até os finais da década de 1970, já no século $X X$, com a predominância de comunidades pesqueiras marítimas e seus modos de vida específicos.

A referida pouca funcionalização do litoral possibilitava certa mobilidade para esses trabalhadores do mar, que podiam se transferir para outros pontos do litoral à procura de bons pesqueiros, por conta da transgressão marinha, da movimentação dos campos de dunas, entre outras motivações. O fato possibilitou, já em tempos mais recentes, a formação e a consolidação do Cumbuco, que até após a construção da Vila (1978) recebeu famílias de pescadores do município de Beberibe. As próprias moradias, construídas com varas de madeira ou de palha (caso do "Cumbuco Velho") que apresentam uma nítida influência das comunidades indígenas - históricos habitantes que viviam de forma nômade no litoral cearense -, caracterizam essa mobilidade, pois facilmente eram construídas ou desfeitas, diferentemente de uma residência de alvenaria, por exemplo.

Essa realidade manteve-se mesmo com as históricas políticas de normatização e fixação no território, principalmente com a criação das "Colônias de Pescadores", em 1922, que apresentam uma estrutura semelhante às "guildas" espanholas, em que podem exercer a profissão somente os pescadores cadastrados em suas respectivas colônias (DIEGUES, 1995).

Uma cumbuqueira, que reside na localidade desde a época do "Cumbuco Velho", destaca que as famílias, ao chegarem, procuravam um "Iugarzinho vazio", construíam suas casas e delimitavam seus terrenos com troncos de árvores fincados ao chão e com a plantação de fruteiras, embora essa delimitação nem sempre ficasse livre de pequenos conflitos.

De acordo com relatos de moradores antigos, Cumbuco era caracterizado principalmente pela enorme quantidade de lagoas interdunares com peixes em abundância, pelos grandes campos de dunas e pela existência das áreas de vazantes, onde eles trabalhavam em pequenas produções para

\footnotetext{
${ }^{7}$ Como hodiernamente os moradores chamam o Cumbuco antes de se tornar Vila.
} 
complementar a subsistência das famílias. Segundo Lima (2006), uma das ações que identificam as comunidades tradicionais, principalmente pesqueiras, é a prática de combinar várias atividades econômicas dentro de um complexo calendário.

Com o intuito de complementar a subsistência das famílias, plantava-se, nas vazantes, arroz, feijão, milho, batata doce, mandioca, jerimum, entre outros produtos, além de manter criações de animais de pequeno porte: porcos, galinhas, entre outros. Na quadra invernosa, essas pequenas produções que, segundo Cascudo (1957), eram preparadas pelos homens e tocadas principalmente pelas mulheres, garantiam quase totalmente a subsistência das famílias, pois nesse período o mar é mais revolto, o que dificultava a atividade da pesca.

A principal atividade econômica era a pesca, o que Diegues (1995, 1996) vai denominar pequena produção mercantil, caracterizada pela pesca artesanal voltada sobretudo para a venda, mesmo que parte da produção fosse destinada à subsistência familiar. Semanalmente, no período de maré baixa, os marchantes, oriundos de Fortaleza ou Caucaia, chegavam com seus Jeeps para a compra dos pescados.

No início da formação do Cumbuco, as mulheres não tinham muitas alternativas para a geração de renda, ficando encarregadas de cuidar da casa, dos filhos e das pequenas plantações e criações. Todavia, com o passar do tempo, foram aprendendo e difundindo técnicas de bordados, labirintos, rendas, entre outros produtos artesanais, comercializados em Caucaia e Fortaleza, e também vendidos a pessoas que visitavam a comunidade.

Entretanto, no contexto da busca de novos territórios e setores para a acumulação capitalista, como também da subordinação do tempo livre e das demais relações sociais que escapavam à lógica da (re)produção das relações sociais de produção capitalista, o litoral passou a ser fortemente funcionalizado ${ }^{8}$, gerando uma séries de conflitos. Dantas (2006) destaca que os anos 1970 simbolizam um movimento importante de transformação e

\footnotetext{
${ }^{8} \mathrm{O}$ tema da valorização e da funcionalização do litoral do Ceará foi desenvolvido em Cavalcante (2012).
} 
incorporação do litoral cearense à sociedade de consumo $^{9}$. E com esse movimento, "o pescador, que antes se batia contra o mar e seus elementos para garantir sua sobrevivência, tem que bater-se em terra parra garantir sua permanência nas praias". (DANTAS, 2007, p.272).

Tratando especificamente do Cumbuco, em 1972 um empreendedor conheceu a comunidade e pouco tempo depois iniciou estudos de viabilidade e de reconhecimento da área. Naquele período tornou-se comum a vinda de visitantes convidados pelo empreendedor com o intuito de conhecer o local e de realizar futuros negócios. Exatamente, em seis anos, contados da "descoberta" do Cumbuco até a data da inauguração da Vila, muitas coisas aconteceram, como também nos anos que se sucederam.

Parte das terras que futuramente se tornaria a Vila do Cumbuco e o Loteamento Praia do Cumbuco pertencia à Marinha do Brasil, sob o DecretoLei ํㅜ 9.760, de 15 de setembro de 1946, que afirma que as terras de marinha vão até $33 \mathrm{~m}$ da linha da preamar e seus acrescidos, podendo chegar, na prática, até 100 ou $200 \mathrm{~m}$ de orla. E a empresa, "[...] sabedora deste fato, solicitou então que a União fizesse a demarcação das terras naquela praia" (PINHO, 1981, p. 23).

O restante das terras, segundo dados oficiais da empresa, "[...] era uma fazenda abandonada, mas tinha uma escritura desde 1848. Essa Fazenda era dividida em duas partes (Parnamirim e Jabaquara), e pertencia a uma senhora cujo nome era Caetana Tereza das Maravilhas, com Registro Imobiliário em 1892" (CONSTRUTORA CUMBUCO LTDA, 1997, p. 1).

O empreendedor articulou-se com a Prefeitura de Caucaia, com o Governo do Estado do Ceará, com o Ministério do Trabalho e a Capitania dos Portos, entre outros órgãos e entes políticos, formando uma verdadeira frente de transformação do litoral de Caucaia. Nesse sentido, após uma série de discussões e da elaboração de alguns planos que procuravam decidir o futuro daqueles históricos povoadores do litoral, deliberou-se construir a Vila do Cumbuco. Dessa forma, a Construtora Cumbuco LTDA, ficou responsável pelo

\footnotetext{
${ }^{9}$ Movimento que irá se intensificar na segunda metade dos anos 1980.
} 
fornecimento do material de construção de 80 casas em troca de alguns benefícios da Prefeitura de Caucaia, do Governo do Estado, da Superintendência Nacional do Abastecimento (SUNAB) e do Ministério do trabalho. Segundo Pinho (1981, p. 25-26, grifos da autora) os benefícios foram:

\begin{abstract}
a) A prefeitura de Caucaia concedeu à construtora isenção de impostos referentes a toda a área a ser loteada, o que significa que, enquanto lhe pertencer, nenhum imposto incidirá sobre a terra. No entanto, a partir da venda de cada lote, a prefeitura começa a cobrar impostos, agora do novo proprietário.

b) Ao Governo do Estado coube a instalação de energia elétrica na nova vila, passando, obrigatoriamente, pelo loteamento. Também este se comprometeu a entregar asfalto líquido à construtora para ser aplicado na estrada que vai da praia da Tabuba até a Vila.

c) À SUNAB coube o fornecimento de $\mathrm{Cr} \$ 200.000,00$ para compra de alimentos destinados aos operários que estivessem trabalhando na obra da nova vila.

d) O Ministério do Trabalho contribuiu permitindo que as casas fossem construídas em regime de mutirão. Isto significa que os operários trabalhariam sem carteira assinada, ficando 0 empregador, no caso a Construtora Cumbuco, desobrigada de cumprir qualquer encargo trabalhista, tal como pagamento de décimo terceiro mês, previdência social, férias, e outros direitos que são devidos aos trabalhadores com carteira assinada, ou seja, que mantenham vínculo empregatício com a firma empregadora.
\end{abstract}

No dia 7 de janeiro de 1978, às 16 horas, foi inaugurada a Colônia Z-7 de pescadores de Cumbuco. Foram construídas 80 casas para as famílias que permaneceram, mas, conforme dados oferecidos pela Colônia e pelos documentos da construtora, foram entregues apenas 79 casas, pois uma família optou pelo recebimento de uma indenização e foi morar no litoral do Rio Grande do Norte. A casa que ficara vazia, então, foi destinada a sediar a maternidade.

As casas "doadas" eram divididas em oito "vilas"10 (quarteirões) formadas por 10 casas geminadas constituídas por dois quartos, sala, cozinha (com uma pia), banheiro (com um tanque d'água e aparelho sanitário, sem descarga e sem tampa), tanque para lavar roupas, fossa e sumidouro. Não existia instalação hidráulica ou elétrica, apenas dois poços para toda a vila,

\footnotetext{
${ }^{10} \mathrm{Na}$ linguagem dos moradores da localidade.
} 
nem existia calçada nas casas (CONSTRUTORA CUMBUCO LTDA, 1997; PINHO, 1981).

As casas foram construídas em lotes de $180 \mathrm{~m}^{2}$, possuindo $36 \mathrm{~m}^{2}$ de área construída (seis por seis), $42 \mathrm{~m}^{2}$ de cobertura, paredes de alvenaria, sem revestimento (reboco) e somente com pintura externa na cor branca; portas de madeira comum e sem forramentos; piso interno vassourado na sala e nos dois dormitórios; piso cimentado na cozinha e no banheiro (PINHO, 1981).

Os cumbuqueiros, que moravam de modo espraiado em toda a área que compreende o Cumbuco, foram realocados para essa pequena vila de 50.616 $\mathrm{m}^{2}$ distribuída em $23.400 \mathrm{~m}^{2}$ de área loteada, $22.896 \mathrm{~m}^{2}$ de ruas e $4.320 \mathrm{~m}^{2}$ para serviços comunitários, esportes e sede da colônia. Da área loteada, apenas $14.400 \mathrm{~m}^{2}$ foram realmente ocupados naquele momento, ficando 48 lotes destinados ao crescimento da Vila.

O restante das terras do Cumbuco foi destinado à construção do Loteamento Praia do Cumbuco, que teve seu primeiro lote vendido oito meses após a construção da Vila. Toda a área loteada foi beneficiada com energia elétrica, via de acesso asfaltada e linha de ônibus que fazia o percurso Cumbuco/Caucaia cinco vezes ao dia. Assim, em meados dos anos de 1980, "[...] próximo à Vila onde antigamente só existiam dunas e coqueirais, começam a surgir quarteirões de casas de veraneio" (PINHO, 1981 p. 6).

Os primeiros problemas surgidos após a construção da Vila foram a falta de espaço destinado às pequenas produções de subsistência da população e para a criação de pequenos animais, e conflitos entre a vizinhança pelo fato de as casas - antes distantes umas das outras - terem se tornado geminadas. Uma cumbuqueira entrevistada destaca que teve problemas com seus vizinhos por causa de suas criações e que recebeu várias advertências do empreendedor, por intermédio de seus capatazes. Mesmo depois da construção da Vila, o empreendedor agia fortemente na regulação da vida dos moradores.

Os cinco quarteirões que ficaram vazios foram sendo ocupados aos poucos pelos filhos dos moradores que casavam e começavam a formar suas famílias. Todavia, na metade da década de 1980, os lotes vazios que restavam 
foram ocupados pelos pescadores de Beberibe, que se transferiram para 0 Cumbuco, por conta do auge da pesca do camarão na localidade e de conflitos por terra em seu município de origem.

Em 1986, período marcado pela força da urbanização litorânea, o jornal O POVO publicou que "[...] no Cumbuco, o vilarejo persiste, mas também está sufocado pelas mansões", em reportagem que tratava das pressões que os pescadores sofriam para ceder lugar aos especuladores imobiliários em Fortaleza e na Região Metropolitana (O POVO, Dia 7 de fevereiro de 1986).

Ainda em 1986, em outra reportagem do Jornal O POVO, lia-se a afirmativa de que o "[...] Cumbuco tem 100 casas de pescadores e 200 de veraneio que, sem dúvida, são as mais belas da Costa Litorânea Cearense" ( $O$ POVO, Dia 12 de outubro de 1986).

No final da década de oitenta, já com a construção do hotel Saint Tropez des Tropiques, Cumbuco se torna um marco para o turismo cearense, especificamente com relação ao turismo internacional, pois chegavam os primeiros voos charters, que traziam turistas diretamente para 0 empreendimento hoteleiro francês pela empresa aérea Air France. A empresa espalhava naquele momento por toda a Europa cartazes e folders da "[...] operadora de turismo 'El Condor', convidando os civilizados a descobrirem este paraíso, um Éden de sol eterno, águas tépidas e brisa amena que suaviza o calor." (O Povo, 12 de agosto de 1988). Entre o período de fevereiro de 1989 e janeiro de 1990, cerca de 1100 franceses chegaram pelo aeroporto de Fortaleza para se hospedar no citado hotel (O Povo, 19 de janeiro de 1990).

\subsection{Da "invenção" à superação do cumbuco}

O recuo histórico das páginas anteriores não se deu a esmo, mas, sim, pelo fato de a história local ser, por vezes, desconhecida das novas gerações de cumbuqueiros e mais ainda dos turistas, investidores e veranistas que se deslocam de vários cantos do Brasil e do mundo. História que foi se perdendo no decorrer dos anos, sendo substituída por uma história oficial divulgada a todo o momento pelos trades turísticos, especuladores, investidores, entre 
outros, que caracterizam o "Cumbuco Velho" como o Cumbuco do atraso, do analfabetismo, da mortalidade infantil, entre outras características degradantes:

\begin{abstract}
Em 1976 não havia água tratada, energia, telefone, posto médico, escola pública, e como já citado, nenhuma estrada. A taxa de analfabetismo era de quase $100 \%$. Os nativos contam que nessa época a taxa de mortalidade infantil chegava a $80 \%$, durante o primeiro ano de vida. A taxa de mortalidade de parturientes era altíssima, devido a falta de higiene no parto e no pós-parto, além da falta de assistência médica. Em casos de doenças, os moradores dessa vila precisavam andar quase $20 \mathrm{~km}$ por cima das dunas, transportando o doente numa rede ou no lombo do cavalo e geralmente chegavam tarde demais no hospital mais próximo, em Caucaia. ${ }^{11}$
\end{abstract}

Um dos documentos da Construtora Cumbuco LTDA $^{12}$ apresenta uma "História resumida do Cumbuco", trazendo praticamente as mesmas informações da citação acima, afirmando que, após a construção da Vila, "de cada 320 (trezentos e vinte) crianças que nasciam [...] apenas 1 (uma) morria e [que] nenhuma mulher morreu de parto. Todas as crianças da Vila estudam lá, ninguém paga aluguel nem transporte para ir trabalhar" (CONTRUTORA CUMBUCO, 1997, p. 2-3). O referido documento assegura, também, que "o Cumbuco passou a ser assim, o único local de pesca, que convive com nativos e novos proprietários, sem confusão e pelo contrário, em muita harmonia". (CONTRUTORA CUMBUCO, 1997, p. 2).

No intuito de enfatizar que o processo se deu sem grandes conflitos, o citado documento menciona, ainda, que apenas uma família decidiu receber a indenização e foi morar no litoral do Rio Grande do Norte, como destacado anteriormente, deixando de nomear as outras cerca de 40 famílias $^{13}$ que, ainda aproveitando os últimos momentos da referida mobilidade, se mudaram para outras paragens do litoral cearense e nordestino, como uma família que fora para uma comunidade pobre do litoral de Fortaleza, conhecida como

11 Extraído do site <http://www.visiteobrasil.com.br/historiasdascidades/ce-cambuco.php>. Acesso: 04 de setembro de 2010. Site especializado em turismo, que apresenta informações privilegiadas como um detalhamento cronológico de vários acontecimentos no Cumbuco e até informações pessoais do dono da Construtora Cumbuco Ltda.

12 Ver em Construtora Cumbuco LTDA (1997).

${ }^{13}$ Ver Pinho (1981). 
Arpoador $^{14}$. Todos os esforços foram utilizados no intuito de instituir essa história oficial em detrimentos dos vários registros de recusa e conflitos.

Uma cumbuqueira, por exemplo, enfatiza que

\begin{abstract}
Tiraram essa madeira e trouxeram. Aí colocaram acolá, onde hoje é [...] aquele pé de azeitona [que] fui eu que plantei e plantei um bocado de pé de coqueiro e cajueiro que o finado Osmar arrancou todinho, dizendo que era a mandado do doutor [...] Eles estavam fazendo essas casas aqui para a gente se mudar para cá. Aí eu disse: - Eu não me mudo para ali, eu não vou. Eu fico é aqui na minha casa. Era tão bonito!

Eu mandei dizer para o doutor [...] que eu não vinha para cá. Ele podia dar a casa para quem ele quisesse, mas eu não vinha. Aí ele disse: - Ela tem que ir, porque ali vai ser casa de veraneio. Aí eu disse: - Olhe!Eu não deixo. Eu não vou sair de dentro da minha casa para ninguém derrubar. A minha casa aqui é de palha, deixa ele com o sobrado dele, mas eu não quero.

Briguei, briguei, briguei e fui embora. Todo mundo ganhou casa aqui e eu nada. O doutor mandava dizer: Diga a ela que venha receber a casa dela senão eu dou para outro. Eu disse: - Olhe! Pode dar. Eu já estou na minha casa.
\end{abstract}

Pinho (1981, p. 36), também transcreve uma série de depoimentos de cumbuqueiros descontentes com a mudança, como por exemplo:

\footnotetext{
Vim morar nesta casa porque não tinha para onde ir. Eu queria ficar lá onde eu morava porque lá eu achava melhor, era tudo aberto, não era cercado, não era imprensado como aqui. Aqui é muito quente, é muito pequenininho.

Eu não queria vir prá cá porque tinha pena de deixar minhas lavouras, minhas plantações de milho, feijão, batata, mamão, cana $[\ldots]$
}

Todavia, da mesma forma que nem tudo ocorreu na perfeita harmonia, realmente algumas famílias gostaram da troca de sua antiga moradia pela casa da Vila, como também das mudanças ocorridas, de modo geral, principalmente as famílias mais humildes financeiramente, que muitas vezes não possuíam vazantes e enxergavam a construção da Vila, naquele momento, como uma possibilidade de melhoria de vida.

Segundo relatos informais de uma cumbuqueira estudante da escola de educação infantil e fundamental Helena de Aguiar Dias nos tempos de infância, vários eventos da escola contavam com a presença do empreendedor,

${ }^{14}$ Segundo relatos de uma cumbuqueira entrevistada. 
afirmando que ela e os amigos aprendiam que ele era o "Pai do Cumbuco"15. Uma espécie de Martins Soares Moreno da contemporaneidade - mito fundador do Cumbuco.

O empreendedor - que possui uma residência do lado da Vila - não marcava presença apenas nos eventos locais importantes, mas estava corriqueiramente intervindo no dia a dia dos cumbuqueiros, como chamando a atenção de algumas cumbuqueiras por conta da criação de pequenos animais, ou entrando em conflito com outro cumbuqueiro, pois este último queria fazer uma barraca de palha para vender comida e bebida para os frequentadores da praia, ou seja, regulando fortemente a vida dos cumbuqueiros. Existia toda uma relação paternalista e ao mesmo tempo conflituosa entre os cumbuqueiros e o empreendedor, como ainda hoje ocorre entre os cumbuqueiros e o leque de empreendedores que lá investem, por intermédio de uma rede de relações observada também entre os pescadores da Praia de Iracema, em 1941, por Neves (2004) e ainda por Cascudo (1957), ressaltando, de forma genérica essa característica - paternalista e conflituosa - no conjunto de relações estabelecidas e alimentadas pelos pescadores.

Entretanto, é importante destacar que a ideia inicial do empreendedor não era a construção da Vila, o que só veio à tona após várias negociações. Não obstante, sua construção representou a maior propaganda para o turismo e o veraneio no Cumbuco, convidando "os civilizados [turistas europeus] a descobrirem este paraíso ${ }^{16 "}$ que, além do sol eterno, das águas tépidas e dos bons ventos, oferecia contato com uma vila de pescadores, presenciando suas práticas, seus costumes, e todo um leque de experiências com uma comunidade tradicional e seu modo de vida específico. Um exemplo desse marketing foi o próprio hotel Saint Tropez des Tropiques que, mesmo sendo cinco estrelas, tinha seus quartos em formato de cabanas, também chamados

\footnotetext{
${ }^{15}$ Um colunista do Jornal O POVO, possuidor de uma residência no Cumbuco e investidor da localidade, nomeia o empreendedor de o "Pai da praia" (O POVO, 14 outubro de 2010).

${ }^{16}$ Folder da operadora de turismo El Condor, reproduzido em O Povo, 12 de agosto de 1988.
} 
de bangalôs ${ }^{17}$, com teto de palha para dar o caráter rústico, fazendo referência às tradicionais moradias de pescadores.

Um dos folders do Loteamento Praia do Cumbuco apresenta a seguinte passagem: "Tudo isto é o Cumbuco, a sua praia. É o lugar onde você vai ser feliz. No Cumbuco você entra em profunda comunhão com o planeta e leva uma vida ao natural. Você vai se dourar sob um sol generoso porque sempre é verão. Você vai comer um peixe fresquinho que as jangadas trazem ao final das tardes. Você vai tomar água de coco colhido na hora". ${ }^{18}$

Antes mesmo do início das obras de construção da Vila, o empreendedor levava prováveis investidores e possíveis compradores do futuro loteamento para conhecerem o Cumbuco e terem contado com o modo de vida dos cumbuqueiros, estes muitas vezes comparados com índios, como aponta uma idosa cumbuqueira.

Além do marketing, os empreendimentos no Cumbuco foram benquistos por uma parte da opinião pública e pela mídia ${ }^{19}$ da época, pois, afinal de contas, os cumbuqueiros conseguiram permanecer, pelo menos naquele momento, em uma parcela de seu território original, o que foi considerado pela mídia - como já dito anteriormente - um "exemplo de como organizar uma sociedade pobre, sem criar problemas sociais" (O POVO, 30 de novembro de 1979, grifo nosso).

Pinho (1981, p. 16-17), já naquele momento, percebera que a "doação" das casas, como até hoje é divulgado e como consta na escritura das residências, representou "[...] mais uma estratégia para o aumento da valorização de terrenos utilizados pelos especuladores imobiliários [...]". Todavia, é bom salientar que no momento que são questionados sobre o processo de doação das casas, os cumbuqueiros sempre destacam que as casas foram trocadas por suas antigas moradias e vazantes, não sendo

\footnotetext{
${ }_{17}^{17}$ O Povo, sexta-feira, 22 de setembro de 1989.

${ }^{18}$ Fonte: Colônia Z-7 Cumbuco.

19 Em dia 18 de junho de 1989, um artigo do jornal O POVO transcrevia as palavras do empreendedor que afirmara ter sido a construção da Vila o "primeiro projeto de desfavelamento no Brasil" (PEREIRA, 2012, p. 237).
} 
meramente doadas. Ainda tratando da "doação" das residências, Pinho (1981, p. 35) transcreve o relato de um cumbuqueiro: "eles falam que aqui foi dado, mas não foi não, porque aqui, no Cumbuco velho, cada um de nós tinha sua casinha, seus esquerais, aí apareceu este doutor e foi comprando por mais ou nada".

Gonçalves (2007), fazendo um panorama sobre a temática ambiental nos artigos do Jornal O Povo, apresenta uma reportagem denominada "Pobres e Ricos têm culpa na devastação", de 6 de junho de 1989, noticiando a primeira Conferência Estadual do Meio Ambiente. A reportagem chamava a atenção para as manifestações da sociedade contra empreendimentos predatórios no litoral cearense, comentando também uma carta aberta divulgada por um partido político, que, além de outras coisas, criticava o fato de o hotel Saint Tropez des Tropiques transformar a praia do Cumbuco em uma colônia de férias exclusiva para turistas europeus. As amenidades naturais e a Vila eram as principais atrações.

É de conhecimento de todos no Cumbuco uma pequena desavença entre duas idosas cumbuqueiras que disputam o título de primeira professora do Cumbuco, pois a senhora que detém tal título, desde a chegada do empreendedor, recebe turistas e visitantes, de modo geral, para contar como era a escola antes e depois da construção da Vila. Ainda nos dias de hoje, mesmo que de forma menos organizada, o visitante que procura conhecer a história (oficial) do Cumbuco é levado ao encontro de pessoas que desde a construção da Vila desempenham o papel de contar uma série de narrativas sobre o Cumbuco.

Esses narradores selecionados também ajudaram a divulgar a história oficial do Cumbuco, como se pode observar na afirmação de uma cumbuqueira, ao descrever a chegada de visitantes trazidos pelo empreendedor antes da construção da Vila: "quando o doutor [...] trazia o povo [...] aí eu pegava e mandava os meninos sentarem no chão, mas tinham as cadeiras né. Os homens diziam assim: - Mas que escola pobre é essa? E esse prefeito o que é que está fazendo que não trouxe as cadeiras?" 
A própria casa de palha onde funcionava a escola do Cumbuco foi mantida após a construção da Vila para mostrar aos visitantes "a grande transformação física" pela qual tinha passado a antiga comunidade (PINHO, 1981, p.01).

Vale destacar que, durante o percurso da pesquisa, "naturalmente" se indicavam esses históricos narradores para as entrevistas. Essa circunstância, mesmo diante das limitações, não impossibilitava uma entrevista carregada, também, de críticas a todo o processo ocorrido, tanto pela relação paternalista/conflituosa destacada antes, como também pelo fato da memória ter uma relação direta com o presente, como nos indica Bosi (2010), que propiciava aos referidos cumbuqueiros uma espécie de avaliação pessoal de tudo o que ocorreu confrontado com a realidade atual ${ }^{20}$.

Em outras comunidades pesqueiras marítimas do estado do Ceará sabese que os fatos ocorreram diferentemente. Lima M. (2002) destaca que algumas comunidades conseguiram formar um forte movimento em torno da iniciativa comum de garantir a manutenção de seus modos de vida, articulandose interna e externamente a outras comunidades que enfrentavam os mesmos problemas, de modo a formar verdadeiras frentes de luta e resistência.

Entretanto, no Cumbuco, os processos se deram de maneira um pouco distinta do que aconteceu em outras comunidades do litoral cearense, pois, em grande parte dos casos, o especulador chegara com uma escritura, por vezes de caráter duvidoso, reivindicando toda a área ou parte dela onde viviam tais comunidades e exclamando que as famílias - viventes naquelas terras há gerações - teriam de deixar suas casas e procurar um novo local para morar, como foi pessoalmente visto na comunidade de Caetanos de Cima (Amontada$\mathrm{CE}$ ) e em Canto Verde (Beberibe-CE), por exemplo. No Cumbuco, porém, o empreendedor logo tratou de pedir o aforamento das terras e se articulou com órgãos públicos municipais, estaduais e federais, em prol do seu projeto de desenvolvimento do veraneio e da atividade turística no litoral de Caucaia.

\footnotetext{
${ }^{20}$ Neves (2004, p. 50), destaca que "[...] certas relações paternalistas que almejam e realizam a deferência, não são capazes de impedir atos de rebeldia, ou, como é o caso, de denúncia contra aqueles mesmos que lançam suas redes de assistência".
} 
Grande parte dos cumbuqueiros, mesmo não querendo sair de suas casas, o que gerou alguns conflitos individuais, como destacado, não se articularam ativamente no intuito de resistirem e logo ficaram desacreditados com toda a legitimação dada pelos órgãos oficiais. Tal realidade foi fundamental para o empobrecimento da identidade dos cumbuqueiros com o passar dos anos, pois, como afirma Bonnemaison (1981), a resistência, a partir dos conflitos com a sociedade urbana, é a maior reforçadora da identidade das comunidades tradicionais, no caso, das comunidades pesqueiras marítimas do estado do Ceará.

A Vila do Cumbuco transformou a histórica comunidade pesqueira marítima em uma paródia de si mesma, a partir de uma teatralidade ${ }^{21}$ regulada e vendida tanto nos pacotes turísticos nacionais e internacionais quanto para 0 veraneio daqueles que sonhavam em passar seus fins de semana longe da rotina das metrópoles, contemplando a natureza e em contato direto com a vida pacata de uma vila de pescadores. Foi criada a imagem de que a Vila do Cumbuco era uma continuidade evoluída da antiga comunidade pesqueira marítima, agora livre dos males do passado, como a pobreza, dificuldade no acesso aos serviços de saúde, analfabetismo e isolamento.

Damiani (Mimeo, $\mathrm{s} / \mathrm{d}$ - grifo nosso) afirma que a atividade do turismo é organizada integralmente, desde hotelaria, trajetos programados, diversões e paisagens escolhidas e administradas. Mediante um "jogo de imagens e palavras, envolvendo coisas e pessoas, monta-se 0 cenário, não necessariamente coincidente com o real".

Um novo Cumbuco foi "inventado", na acepção de Hobsbawm (1984), não no sentido de se buscar tradições remotas que se perderam nas brumas do tempo histórico, mas a partir de uma continuidade artificializada de todo um leque de costumes e práticas que caracterizavam um modo de vida que até aquele momento se conservara/adaptara, mas que acabara de ser estilhaçado pela força do espaço abstrato, sendo vendido como mercadoria nos pacotes turísticos.

\footnotetext{
${ }^{21}$ Ver Alfredo (2001).
} 
Para Carlos (1996, p. 109, grifos da autora) o turismo

\begin{abstract}
Transforma tudo o que toca em artificial, cria um mundo fictício e mistificado de lazer ilusório, onde o espaço se transforma em cenário, "espetáculo" para uma multidão amorfa através da criação de uma série de atividades que conduzem a passividade, produzindo apenas a ilusão da evasão e, deste modo, o real é metamorfoseado, transfigurado, para seduzir e fascinar. Aqui o sujeito se entrega às manipulações desfrutando a própria alienação.
\end{abstract}

O território de uso da comunidade pesqueira marítima foi estilhaçado em vários percursos e em diversas atrações para os turistas, veranistas e investidores. ${ }^{22}$ Os cumbuqueiros foram separados de sua obra ${ }^{23}$, no sentido de Debord (1997), uma separação entre a atividade real e sua respectiva representação, em que as relações concretas com o território de uso por eles construídas foram substituídas por uma série de relações simuladas e abstratas, reguladas em prol das atividades econômicas ali instaladas. Cumbuco se tornou um reflexo infiel dos cumbuqueiros.

Os cumbuqueiros, entretanto, não são simplesmente os vitimizados de um jogo de relações que os segregam para 0 deleite das camadas economicamente superiores da sociedade. Bauman (1999) chega a classificar os turistas como seres emancipados, pois deteriam o controle da mobilidade e dos fluxos, podendo vivenciar até uma suposta já comentada desterritorialidade. Todavia, nessa sociedade encurralada entre o político e o econômico, os próprios desejos dos turistas são controlados e os destinos predeterminados e estilhaçados numa série de roteiros e city tours, onde a lógica preponderante é "conhecer" o maior número de locais possíveis no transcorrer do pacote comprado. Não existe tempo para uma construção de relações concretas com o lugar, mas sim apenas para o estabelecimento de uma série de relações efêmeras e sem espessuras. Jappe (2008, p. 52) trabalhando com o pensamento de Debord, afirma que "[...] as próprias classes

\footnotetext{
22 Todavia, ressalta-se novamente que, mesmo estilhaçado, o cumbuco é permeado pela coexistência de várias temporalidades históricas, apresentado uma gama de vestígios de sociabilidades anteriores, como apresentado no início deste quarto capítulo.

23 "A obra desaparece frente ao produto." (LEFEBVRE, 1972, p. 38).
} 
dominantes perderam completamente o domínio; a disputa limita-se agora a encontrar um lugar mais confortável na alienação geral".

Convém ressaltar que não se tem o objetivo de defender a não existência de problemas no Cumbuco antes da construção da Vila, pois, mesmo que até decênios passados o litoral cearense fosse muitas vezes um sinônimo de liberdade, para vários agrupamentos humanos há muito tempo não era inteiramente entendido pelas afirmações que descrevia o pescador como um homem livre e desprovido de mazelas sociais que afetavam os sertões, a exemplo do latifúndio, da seca e da fome.

Os anos de 1910 e 1920, por exemplo, foram marcados pela consolidação do pescado como mercadoria, marcando o surgimento dos marchantes, que praticamente ficavam com todos os ganhos das pescarias, fato que levou quatro pescadores cearenses, em 1941, a viver uma famosa saga de 61 dias em uma pequena jangada de piúba rumo a até então capital federal (Rio de janeiro). O intuito era sensibilizar o presidente Getúlio Vargas a respeito da ausência de leis de amparo ao pescador e, principalmente, denunciar as práticas tanto dos marchantes - que comercializavam o pescado, colocando-se entre o pescador e o mercado consumidor - como também dos donos de jangada, que recebiam metade da produção mesmo ficando no seco (NEVES, 2004).

Segundo Pinho (1981), na época do Cumbuco Velho havia somente um marchante que monopolizava todo o comércio do peixe, que exigia obediência dos pescadores, os quais, por sua vez, não podiam vender sua produção para outros intermediários nem determinar o preço do pescado. Nesse sentido, a produção era levada para Caucaia, todavia os pescadores não tinham a certeza do pagamento, pois caso o peixe apodrecesse ou acontecesse qualquer outro contratempo o pescador ficava no prejuízo.

Até os finais da década de 1970, as lutas dos pescadores eram referentes ao mar. Entretanto, com a funcionalização do litoral como território turístico, foi gerada uma série de novos conflitos que passam a se dar também no "seco", dificultando mais ainda a reprodução da vida e a manutenção do modo de vida das comunidades pesqueiras marítimas do Ceará. 
Contudo, a Vila, que por muitos anos foi a principal catalisadora do veraneio e do turismo no Cumbuco, como acabou de ser destacado, vem sendo encarada em anos recentes como um problema para os gestores e investidores em geral, pois essas atividades econômicas se solidificaram e conseguiram se desvincular, mesmo que ainda de forma ambígua, da venda da antiga imagem local e agora começam a vender a imagem de um Cumbuco consolidado por um turismo de alto nível e um veraneio composto por grandes condomínios, além toda uma infraestrutura que vem em auxílio desses grandes investimentos hoteleiros e imobiliários. Até porque, diante da realidade atual, a venda da imagem de uma pequena vila de pescadores e seu modo de vida específico está se tornando impraticável.

Nesse sentido, as pequenas casas precárias e amontoadas da Vila, as quais ainda permanecem sob a posse dos cumbuqueiros, começam a ser encaradas como um fator limitante a ser superado, tornando-se mote para uma série de obras que visam a requalificação da Vila do Cumbuco, como: saneamento básico, abastecimento de água, drenagem, reforma da praça ${ }^{24}$, pavimentação, entre outras.

Para Antônio Câmara, sócio-proprietário da Cameron, e para Carlos Fiúza, superintendente da Diagonal, as obras de requalificação da Vila representaram um dos motivos que levaram as suas empresas a voltar a investir no Cumbuco (DIÁRIO DO NORDESTE, 22 de outubro de 2011).

Em algumas das conversas informais com os membros da diretoria da colônia, no início de 2011, durante a construção do documentário citado anteriormente, foram relatadas algumas reuniões ocorridas com representantes da prefeitura de Caucaia, onde foi destacado que a ideia dos gestores era transformar Cumbuco numa próxima $\mathrm{Pipa}^{25}$. E no mês de setembro do mesmo ano, o Jornal Diário do Nordeste apresentou uma reportagem em que os próprios investidores e representantes de incorporadores apontavam Cumbuco

\footnotetext{
${ }^{24}$ Segundo reportagem do Jornal O Povo de 31 de novembro de 2011, a Praça do Cumbuco "ganhará novo projeto arquitetônico, com paisagismo e espaço para diversão, entretenimento e compras. Lojas de grifes famosas serão instaladas no espaço." (O POVO, 31 novembro 2011).

${ }^{25}$ Praia Localizada no município de Tibau do Sul, no estado do Rio Grande do Norte.
} 
como uma "futura Pipa", destacando principalmente os fluxos turísticos, investimentos e a vida noturna da praia $^{26}$ (DIÁRIO DO NORDESTE, 8 setembro. 2011).

\section{CONSIDERAÇÕES FINAIS}

Constatou-se que, no âmbito da aparência, Cumbuco se destaca como um dos principais receptores de turistas no estado do Ceará, fenômeno contemporâneo ao processo de urbanização presente desde o final da década de setenta no litoral cearense. Entretanto, tal processo esconde uma realidade na qual a comunidade foi estilhaçada, e os cumbuqueiros que não foram habitar outras paragens do litoral cearense e nordestino foram transferidos para uma vila que ficou conhecida como Vila do Cumbuco. A Vila, que fora um dos principais catalisadores do turismo e do veraneio do Cumbuco, constituiu-se uma paródia da antiga comunidade e as relações concretas com o território de uso foram substituídas por uma série de relações simuladas e abstratas, vendidas como mercadorias para turistas, veranistas e investidores.

De catalisadoras, as pequenas, espremidas e precárias casas da Vila que ainda se encontram habitadas por cumbuqueiros, passaram, em anos recentes, a ser consideradas como um fator problema para gestores e investidores. Nesse sentido, foram tomadas medidas que visam uma requalificação do Cumbuco, abrindo caminho para a possibilidade de construção de um futuro onde os cumbuqueiros que ainda residem na Vila se juntarão aos outros que nos últimos decênios estão se re-territorializando em localidades próximas ao Cumbuco, como o Parazinho, por exemplo, mesmo que estes últimos ainda tenham suas vidas diretamente vinculadas à localidade praiana.

\section{REFERÊNCIAS BIBLIOGRÁFICAS}

${ }^{26}$ Segundo outra reportagem do Jornal Diário do Nordeste, o Cumbuco no período da noite "ganha ares de via de cidade grande, com lazer sem hora para terminar e com restaurantes de cozinha que em nada ficam a dever aos situados nas grandes metrópoles" (DIÁRIO DO NORDESTE, 27 de novembro de 2009). 
ALFREDO, A. Geografia do turismo. A crise ecológica como crítica objetiva do trabalho. O turismo como "ilusão necessária". GEOUSP: espaço e tempo, São Paulo, n.9, p. 37-63, 2001.

BAUMAN, Z. Globalização: As consequências humanas. Rio de Janeiro: Jorge Zahar Editor, 1999.

BENEVIDES, I. P. Turismo e o Prodetur: Dimensões e olhares em parceria. Fortaleza: Edições UFC, 1998.

A Política de Turismo no Ceará e a Capacitação. GEOUSP: Espaço e Tempo, São Paulo, n. 14, p. 31-44, 2003.

BONNEMAISON, J. Voyage Autour du Territoire. L'Espace Géographique, Paris, n. 4, v. 10, p. 249-262, 1981.

BRASILEIRO, L. Quem diria, três melhores. O POVO, Fortaleza, p. 8, 14 out. 2010.

CARLOS, A. F. A. O lugar no/do mundo. São Paulo: Hucitec, 1996.

CASCUDO, L. C. Jangadeiros. Rio de Janeiro: Ministério da Agricultura, 1957.

CAVALCANTE, Eider de Olivindo. MODENIZAÇÃO SELETIVA DO LITORAL: conflitos, mudanças e permanências da localidade do Cumbuco (CE). Dissertação (Mestrado em Geografia) - Centro de Ciências, Universidade Federal do Ceará, Fortaleza, 2012.

CEARÁ enaltecido nacionalmente. O POVO, Fortaleza, p. 6, 12 ago. 1988. CONSTRUTORA CUMBUCO LTDA. Convite de inauguração da colônia de pescadores Z-7 de Cumbuco. Fortaleza, 1978.

. História resumida do Cumbuco. Fortaleza, 1997.

CORIOLANO, L. N.; FERNANDES; L. M. M. Turismo: Ações e contradições da Realidade Cearense. In: SILVA, J. B.; CAVALCANTE, T. C.; DANTAS, E. W. C. (Org.). Ceará: um novo Olhar Geográfico. Fortaleza: Edições Demócrito Rocha, 2007. Cap. 16, p. 399-407.

CUMBUCO vai a Cannes. O POVO, Fortaleza, p. 4, 12 out. 1986.

CARLOS, E. Cumbuco volta a atrair atenção de construtoras. Diário do Nordeste, Fortaleza, 08 set. 2011. Disponível em: $<$ http://diariodonordeste.globo.com/materia.asp?codigo=1038397>. Acesso em: 22 out. 2011.

DAMIANI, A. L. Cotidiano e Turismo. (Mimeo, s/d) 
DANTAS, E. W. C. Mar à Vista. Estudo da Maritimidade em Fortaleza. Fortaleza: Museu do Ceará, 2002.

"Litoralização" do Ceará: Fortaleza, da "Capital do Sertão" a "Cidade do Sol". In: SILVA, J. B.; DANTAS, E. W. C.; ZANELLA, M. E. ; MEIRELES, A. J. A. (Org.). Litoral e Sertão: natureza e sociedade no nordeste brasileiro. Fortaleza: Expressão gráfica, 2006. Cap. 30, p. 245-252.

. O Pescador na Terra. In: SILVA, J. B.; CAVALCANTE, T. C.; DANTAS, E. W. C. (Org.). Ceará: um novo Olhar Geográfico. Fortaleza: Edições Demócrito Rocha, 2007. Cap. 11, p. 15-27.

. La Maritimité Chez les Indiens du Brésil. Géographie et Cultures, Paris, v. 78, p. 75-96, 2011.

. La maritimité sous les Tropiques: les contributions d une étude réalisée à Fortaleza (Ceará). Confins, Paris, v. 20, p. 1-15, 2014.

DEBORD, G. Sociedade do espetáculo. Rio de janeiro: Ed. Contraponto, 1997.

DIEGUES, A. C. S. Povos e mares: leituras em sócio-antropologia marítima. São Paulo: NUPAUB-USP, 1995.

GONÇALVES, J. C. Meio ambiente no jornal O Povo: de 1976 a 1997. In: CONGRESSO BRASILEIRO DE CIÊNCIAS DE COMUNICAÇÃO, XXX, 2007, Santos. $\quad$ p. 1-15. Disponível em: <http://www.intercom.org.br/papers/nacionais/2007/resumos/R1320-1.pdf>. Acesso em: 10 mar. 2012.

HAGUETTE, T. M. F. Metodologias Qualitativas na Sociologia. Rio de Janeiro: Vozes, 1994.

HOBSBAWM, E. Introdução: A Invenção das Tradições. In: HOBSBAWN, E.; RANGER, T. A invenção das tradições. Rio de Janeiro: Paz e Terra, 1984. p. 9-23.

INVESTIMENTOS imobiliários atraem turistas e cearenses. O POVO, Fortaleza, 31 nov. 2011. Disponível em: <http://www.opovo.com.br/app/opovo/economia/2011/10/31/noticiasjornaleconomia,23 25712/investimentos-imobiliarios-atraem-turistas-e-cearenses.shtml >. Acesso em: 16 mai. 2012.

INSTITUTO DE PESQUISA E ESTRATÉGIA ECONÔMICA DO CEARÁ. Perfil básico municipal de Caucaia. Fortaleza: IPECE, 2008.

JAPPE, A. Guy Debord. Lisboa: Antígona, 2008. 
LEFEBVRE, H. El manifiesto diferencialista. México: Siglo Veintiuno Editores, 1972.

LIMA, M. C. Comunidades Pesqueiras Marítimas no Ceará: território, costume e conflitos. 2002. Tese (Doutorado em Geografia) - Faculdade de Filosofia, Letras e Ciências Humanas, Universidade de São Paulo, São Paulo.

Pescadoras e Pescadores artesanais do Ceará: modo de vida, confrontos e horizontes. MERCATOR, Fortaleza, v. 05, n. 10, p. 39-54, 2006. LIMA, L. C. Redes de integração do território cearense: dos caminhos da pecuária às estradas virtuais. In: SILVA, J. B.; CAVALCANTE, T. C.; DANTAS, E. W. C. (Org.). Ceará: um novo Olhar Geográfico. Fortaleza: Edições Demócrito Rocha, 2007. Cap. 12, p. 33-50.

NÚMEROS do Litoral Oeste. O POVO, Fortaleza, 22 ago. 2011. Disponível em: $<$ http://www.opovo.com.br/app/colunas/verticals/a/2011/07/22/noticiasverticalsa ,2270098/numeros-do-litoral-oeste.shtml>. Acesso em: 16 mai. 2012.

MADRUGA, A. M. Litoralização: da fantasia de liberdade à modernidade autofágica. 1992. Dissertação (Mestrado em Geografia) - Faculdade de Filosofia, Letras e Ciências Humanas, Universidade de São Paulo, São Paulo. MINAYO, M. C. S. Pesquisa Social: teoria, método e criatividade. Petrópolis: Vozes, 2008.

NEVES, B. A. Pertencer à nação brasileira: a jangada de São Pedro rumo à Capital Federal (1941). Cadernos AEL: Populismo e Trabalhismo, Campinas, v. 11, n. 20/21, p. 41-81, 2004.

O RENASCER das alegrias e de todas as belezas. O POVO, Fortaleza, 30 nov. 1979.

PEREIRA, A. Q. Veraneio marítimo e expansão metropolitana no Ceará: Fortaleza em Aquiraz. 2006. Dissertação (Mestrado em Geografia) Departamento de Geografia, Universidade Federal do Ceará, Fortaleza.

A urbanização vai à praia: contribuições da vilegiatura marítima à metropolização no Nordeste do Brasil. 2012. Tese (Doutorado em Geografia) Departamento de Geografia, Universidade Federal do Ceará, Fortaleza.

PESCADORES estão cada vez mais longe do mar. Pressionados, eles cedem espaço para mansões. O POVO, Fortaleza, p. 7, 7 de fev. 1986.

PINHO, E. M. M.. A atuação do Capital imobiliário em um distrito pequeno Cearense. 1981. Monografia (Graduação em Sociologia) - Departamento de Ciências Sociais, Universidade Federal do Ceará, Fortaleza.

SAINT Tropez o primeiro cinco estrelas do litoral. O POVO, Fortaleza, p. 6, 22 set. 1989. 
MODERNIZAÇÃO DO LITORAL E O ESTILHAÇAMENTO DA VIDA COTIDIANA: O CASO DE CUMBUCO - CAUCAIA (CE)

SECRETARIA DO TURISMO DO ESTADO DO CEARÁ. Evolução recente do Turismo no Ceará. Fortaleza: SETUR-CE, 2009a.

. Indicadores turísticos 1995/2008. Fortaleza: SETUR-CE, 2009b. . Indicadores Turísticos 1995/2011. Fortaleza: SETUR-CE, 2012.

SILVEIRA, B. R. O MORAR PERMANENTE NA PRAIA: moradia e vilegiatura na localidade praiana do Icaraí - Ce. 2012. Dissertação (Mestrado em Geografia) - Departamento de Geografia, Universidade Federal do Ceará, Fortaleza.

TELES, G. A.. Dinâmicas Metropolitanas Contemporâneas: Caucaia na Região Metropolitana de Fortaleza. 2003. Dissertação (Mestrado em Geografia) - Centro de Ciências e Tecnologia, Universidade Estadual do Ceará, Fortaleza. TURISMO dos ventos. Diário do Nordeste, Fortaleza, 27 nov. 2009. Disponível em: <http://diariodonordeste.globo.com/materia.asp?codigo=697298> Acesso em: 16 mai. 2011.

VIEIRA, M. E. Turismo, produção do espaço e desenvolvimento local no litoral oeste cearense - o caso do Cumbuco. 2000. Dissertação (Mestrado em Geografia) - Departamento de Geografia, Universidade Federal do Rio de Janeiro, Rio de Janeiro. 